\title{
Multi-Layered Cloud Distribution Over Tropical Station Using Radiosonde Humidity Observations and CloudSat Measurements
}

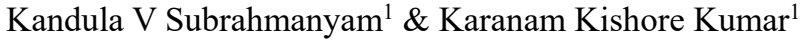 \\ ${ }^{1}$ Space Physics Laboratory, VSSC, Thiruvananthapuram, India \\ Correspondence: Kandula V Subrahmanyam, Space Physics Laboratory, VSSC, Thiruvananthapuram, India. \\ E-mail: kvsm2k@gmail.com
}

Received: May 13, 2019

Accepted: June 4, 2019

Online Published: June 19, 2019

doi:10.5539/enrr.v9n3p9

URL: https://doi.org/10.5539/enrr.v9n3p9

\begin{abstract}
Owing to its importance of role played by multi-layered clouds in climate of earth's atmosphere, a decadal observation (January, 2000 to December, 2009) from India Meteorological Department, Trivandrum regular radiosonde ( 00 \& 12 UTC) ascents and CloudSat observations were used to study the distribution of multi-layered cloud formation at this location. Both the ground and space based observations at Trivandrum locations shows the more or less same percentage of occurrence of single-, double-, three-, four- and five-layered clouds. The important findings are: Radiosonde derived cloud -free cases and one to five cloud layers account for 30.63\%, $42.51 \%, 19.76 \%, 5.85 \%, 1.08 \%$, and $0.16 \%$ all cases, respectively, whereas CloudSat shows $47.17 \%, 24.74 \%$, $6.41 \%, 1.81 \%, 0.13 \%$ of the total samples, respectively. In general, the thickness of cloud layers does not change much from summer to winter. However, the occurrences of multi-layered clouds are more frequent in the summer. Further, keeping the CloudSat limitations in view, an attempt is made to evaluate the CloudSat observations using radiosonde measurements and which has the great potential for studying the multi-layered cloud structures over the globe and important in climate point of view.
\end{abstract}

Keywords: Multi-Layered Clouds, Radiosonde, Humidity, CloudSat

\section{Introduction}

Clouds play an important role in regulating the earth's atmosphere by changing the energy through its horizontal and vertical distribution. The temporal and spatial distribution of cloud systems determine the time and place of the latent heat release, which further alters the changes in general circulation of the atmosphere. Therefore the cloud vertical structure and its base height, top height and thickness are plays pivotal role in modifying the large-scale circulation by changing the total heating or cooling (Webster \& Stephen, 1984). Thus to find the importance of cloud response to general circulation strength, one has to quantify the distribution of cloud vertical structure. Changes in cloud vertical structure depends on the locations of cloud top and base, number of cloud layers and thickness, which affects the atmospheric circulation in atmospheric general circulation models (GCMs) by modifying the distribution of atmospheric latent heating rates (Randall et al., 1989; Wang et al., 1999). There have been a considerable amount of studies in the past on cloud vertical structure distribution (Wang et al., 2000; Jin et al., 2007; Zhang et al., 2010) and which emphatically showed the cloud effects on the general circulation (Wang \& Rossow, 1998). They have examined the response of the atmospheric circulation by varying the cloud vertical distributions in the models. One of the important finding from the previous studies was that the changes in cloud vertical structure play significant role in general circulation strength (Wang et al., 2000). Wang and Rossow (1995) is first to develop a method for retrieving the multi layered cloud information using radiosonde humidity observations and later on there are studies based on this method to study the cloud vertical distribution for different regions (Wang et al., 2000; Zhang et al., 2010). However, very few works have been published concerning multi-layered cloud structure using CloudSat observations (Subrahmanyam \& Kumar, 2018), especially over peninsular region of India based on and radiosonde data (e.g., Narendra et al., 2018). Thus the present study presents the climatological distribution of multi-layer cloud structure over Trivandrum using one decadal radiosonde humidity observations and CloudSat observations.

\section{Data and Methodology}

To derive and study the cloud vertical structures from Trivandrum $\left(8.5^{0} \mathrm{~N} ; 76.9^{0} \mathrm{E}\right)$, downloaded the upper air sounding observations over this location January 2000 to December 2009 from Wyoming University website 
(http://weather.uwyo.edu/upperair/sounding.html). A total 5090 profiles are available during the study period, which are good vertical resolution for deriving the cloud vertical structure information and height coverage also. Figure 1 (a) shows the histogram of balloon burst altitude of radiosondes. Balloon burst altitudes are grouped in six categories such as $10(10-15), 15(15-20), 20(20-25), 30(30-35)$ and $35(35-40) \mathrm{km}$ height levels and counted the number of times radiosonde reached at those altitudes and further calculated the percentage of occurrence. The maximum and minimum percentage of ceiling altitude of radiosonde balloons is $\sim 35 \%$ in $15-20 \mathrm{~km}$ and $\sim 15 \%$ in $10-15 \mathrm{~km}$ height intervals, which is very good for the present analysis. For the present study, Wang and Rossow (1995) method is adopted to derive the number layers of cloud present over Trivandrum. For detailed methodology for deriving the multi-layered cloud information using radiosonde humidity observations, one can read the Wang and Rossow (1995). These relative humidity profiles are sampled at every 100 meters. In a brief, this method takes the humidity profile from radiosonde and applies the thresholds of $84 \%$ and $87 \%$ of minimum and maximum relative humidity to mark as a cloud layer. There are errors associated with this method are 1) systematic biases of radiosonde measurements; 2) the RH cut off mentioned in the analysis 3) the fact that the $\mathrm{RH}$ is always calculated with respect to water at all temperature, which is smaller with respect to ice at temperatures below ${ }^{0} \mathrm{C}$. All these factors imply the underestimation of $\mathrm{RH}$ is radiosonde observations. Accordingly, a cloud can exist at a measured RH less than $100 \%$. On the other hand, it is also possible that no cloud exists when RH is high because other factors such as vertical motion also play a role in cloud formation (Wang \& Rossow, 1995).
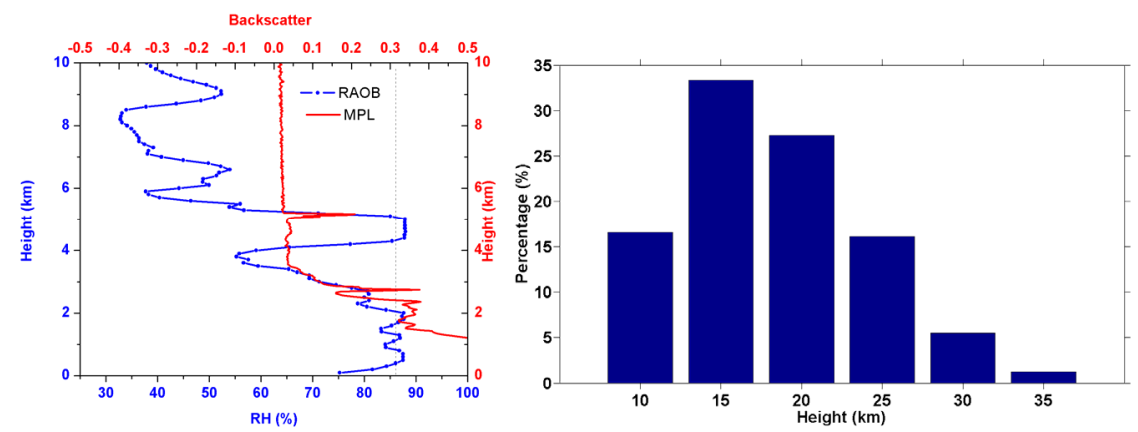

Figure 1. (a) Histogram of balloon burst altitudes of radiosondes; (b) Detection of two layers of cloud by (blue) the radiosonde and (red) the MPL

Apart from this, independently CloudSat observations are used to study the multi-layered cloud structures. Five years (June, 2006-May, 2011) of CloudSat 2B-Geoprof-Lidar data product used for the present study. CloudSat passes are restricted within the radius of $50 \mathrm{~km}$ from Trivandrum. A total 6000 CloudSat profiles are available during the study period at Trivandrum. The maximum number of cloud layers provided by this product is five (Marchand et al., 2008). Monthly frequencies of occurrence of each cloud layers are determined. Further, the present study attempt to compare the CloudSat observations with derived multi layered cloud information from radiosonde, which has the potential use of CloudSat observations for studying the multi-layered cloud structure over the globe and provide the important information to modelling community to better representation of cloud vertical structures. Before studying the statistical distribution of multi-layered clouds, Wang and Rossow (1995) method is verified with observations from Micro Pulse Lidar (MPL) at Trivandrum, which gives the presence of cloud information. Figure 1(b) shows the radiosonde relative humidity (blue colour) and MPL backscatter signal (red colour) on 18 may 2011. The radiosonde releasing time is at 20 IST and MPL is 2030 IST. From Figure 1(b), one can notice that there are four-layered clouds as per this method and MPL also gives signal approximately at those altitudes. Thus, this method is able to detect the cloud layer information from radiosonde relative humidity profile.

\section{Results and Discussion}

10 years of monthly mean of single-, single-, two-, three-, four- and five-layered clouds of radiosonde are shown in Figure 2. These cloud layers are represented by blue, red, black, violet and green colours respectively. Value given inside the each cloud layer box indicates of cloud layer thickness. One can interestingly note that the presence of multi-layered clouds is occurred during June-July-August-September months, which is known as Indian summer monsoon period. By close inspection, there is also multi-layered cloud are present during the months of October and November, which is Northwest monsoon of India. There are well separated layered clouds up to three can observe during the month of April and May receptively. Another interesting feature is that there is clear distance between the single- and double-layered clouds during all the months. The separation 
distance is more during the months from April to September. This could be the pre-monsoon and monsoon effects, where the convective activity is high and also associated with thick tall deep convective cloud. Deep convective clouds are most prominent during the monsoon months of India. Figure 3 represents the frequency of occurrence and percentage of different cloud layers observed by CloudSat. Color bar indicates the fraction of occurrence of cloud layers. 0.7 means $70 \%$ of occurrence of respective cloud layer. As noted in Figure 2, frequency of occurrence of multi layers clouds are more during Indian summer monsoon period and it is evident in Figure 3 as observed by CloudSat. CloudSat also shows the almost similar feature as derived from radiosonde shown in Figure 2. CloudSat also show the presence of multi-layered clouds during Indian summer monsoon period. But there are variations in the average thickness of all clouds with respect to radiosonde derived values. These variations can be attributed to the present methodology for deriving cloud information using RH profile as discussed above section and also the CloudSat data period used in the present study. CloudSat experienced the battery anomaly problem in 2011 and successfully resumed for operation in $27^{\text {th }}$ October 2011 and it re-joined the A-Train in $15^{\text {th }}$ May 2012. Therefore, we have used CloudSat data upto May 2011 in the present study and may be one of the reasons for observed variations between derived cloud layered from radiosondes and CloudSat measurements. However, cloud base values may differ but not their structure.

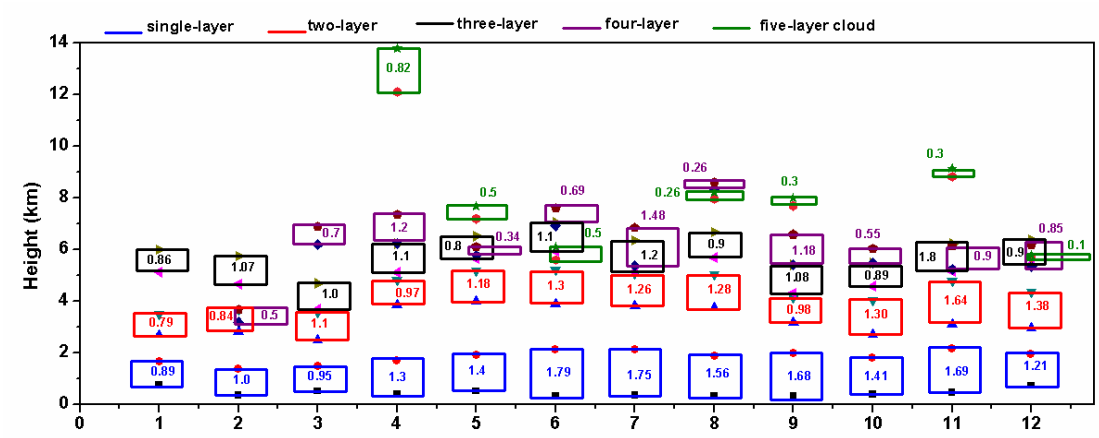

Figure 2. Monthly mean locations and thicknesses of single-, two-, three-, four- and five-layered clouds at Trivandrum

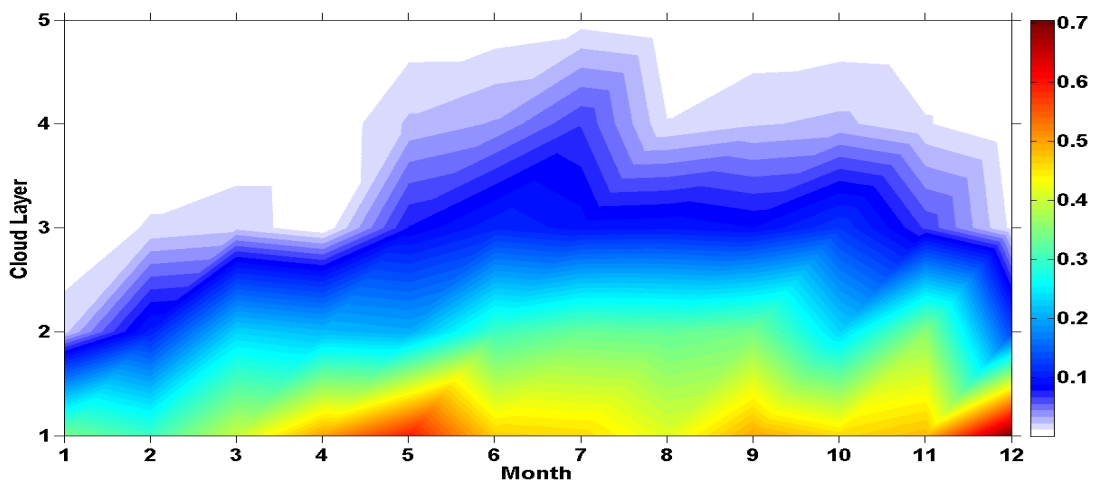

Figure 3. CloudSat monthly frequency of occurrence and percentage of different cloud layers

Figure 4 shows the occurrence of multi-layered clouds (upto 5) derived from radiosonde observations (black) and CloudSat observations (blue) respectively. Radiosonde derived cloud -free cases and one to five cloud layers account for $30.63 \%, 42.51 \%, 19.76 \%, 5.85 \%, 1.08 \%$, and $0.16 \%$ all cases, respectively, whereas CloudSat shows $47.17 \%, 24.74 \%, 6.41 \%, 1.81 \%, 0.13 \%$. Both the ground and space based observations at Trivandrum locations shows the more or less same percentage of occurrence of single-, double-, three-, four- and five-layered clouds. Also shows the frequency of occurrence of clear days. But in the case of percentage of occurrence of clear days, radiosonde is $30.63 \%$ while CloudSat shows $19.78 \%$. There is clear distinct between these magnitudes of percentage and this is mainly because of number of observations. Radiosonde provides at least daily once and maximum twice per day. Whereas CloudSat may not give as like radiosonde and the revisit of CloudSat is $\sim 16$ days on same location (Stephens et al., 2002). 


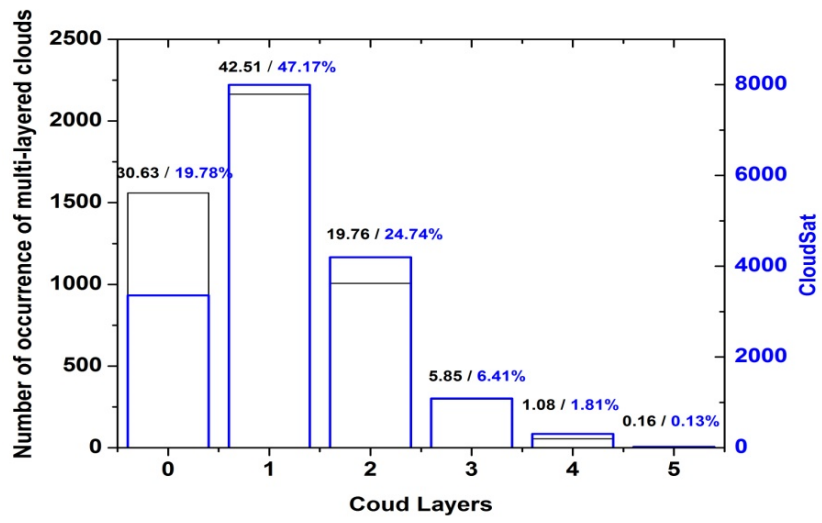

Figure 4. The frequency of occurrence and percentage of different one- to five-layered clouds as observed by radiosnde measurements (balck) and CloudSat observations (blue)
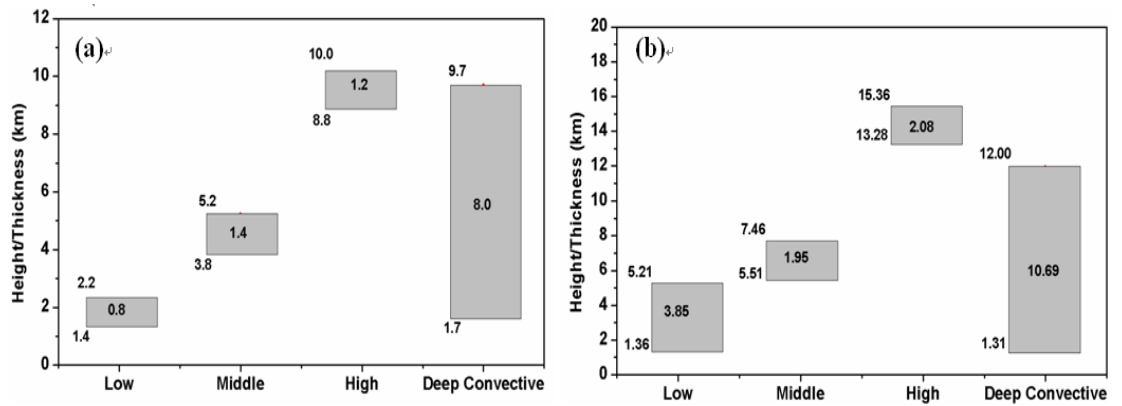

Figure 5. The mean vertical positions and cloud thicknesses for the four types of clouds derived from by (a) radiosonde measurements and (b) CloudSat observations respectively

The mean localities of single-, double-, three-, four-and five-layered clouds of radiosonde and CloudSat are also estimated. The mean thickness of single-layered cloud is greater than the thickness of other high level clouds. The mean base height of the single-layered cloud is $422 \mathrm{~m}$, whereas the base of two-layered cloud is $3.34 \mathrm{~km}$. And the three-, four- and five layered cloud base is 5.15, 5.95 and $8.05 \mathrm{~km}$ respectively. For CloudSat is $6.52,10.57,12.32$, $13.96,14.30 \mathrm{~km}$ respectively. It should be noted that the radiosonde humidity observations are limiting for altitude below $10 \mathrm{~km}$, whereas CloudSat is able to provide the information above $10 \mathrm{~km}$. Because of this, the maximum CloudSat cloud layer base is $14.30 \mathrm{~km}$ and its top height is $15.96 \mathrm{~km}$. By combining the radiosonde and CloudSat one will get the comprehensive picture of multi-layered cloud at a given locations. Further, clouds are classified into four groups: (1) low clouds with bases lower than $2 \mathrm{~km}$ and thicknesses less than $6 \mathrm{~km}$; (2) middle clouds with bases ranging from 2 to $6 \mathrm{~km}$; (3) high clouds with bases greater than $6 \mathrm{~km}$; and (4) vertically developed clouds with bases less than $2 \mathrm{~km}$ and thicknesses greater than $6 \mathrm{~km}$ as per WMO classification. The mean positions and cloud thicknesses for the four types of clouds are shown in Figure 5 ( $\mathrm{a} \& \mathrm{~b}$ ) for radiosonde and CloudSat observations respectively. Thickness of all clouds shown in figure 5 varies for both the observations. Radiosonde shows $1.4,3.8$ and $8.8 \mathrm{~km}$ for base of low, mid and high level clouds, whereas CloudSat shows the 1.36, 5.51 and $13.28 \mathrm{~km}$ respectively. As noted in methodology section, radiosonde base humidity measurements are valid upto around $-40^{\circ} \mathrm{C}$ and limiting the high level cloud base and its height. Same is the reason for deep convective cloud height, where CloudSat shows the $12 \mathrm{~km}$ mean cloud top. Overall, both the ground and space observations show the more or less same structural behaviour within their limitations. Thus the present study provides the complete picture of knowledge about the occurrence of multi-layered clouds at Trivandrum. This information is very useful for modellers for better representation of multi layered clouds in Global Circulation Models and plays an important role in radiative dynamics of the atmosphere.

\section{Conclusion}

The cloud detection method used in this study is based on the Wang and Rossow (1995) for relative humidity profile at Trivandrum. The RH profile is then examined by applying above method to identify cloud layers at this location and applied to 5000 individual radiosonde atmospheric RH profiles form January, 2000 to December 2009. Cloud detection based on radiosonde measurements compares very favourably with MPL data. Derived the 
first comprehensive cloud vertical structure data set at Trivandrum from radiosonde and space based CloudSat observations. The main findings are as follows: Radiosonde derived cloud -free cases and one to five cloud layers account for $30.63 \%, 42.51 \%, 19.76 \%, 5.85 \%, 1.08 \%$, and $0.16 \%$ all cases, respectively, whereas CloudSat shows $47.17 \%, 24.74 \%, 6.41 \%, 1.81 \%, 0.13 \%$ of the total samples, respectively. In general, the thickness of cloud layers does not change much from summer to winter. However, occurrences of multi-layered clouds are more frequent in the summer. Further, an attempt is made to evaluate the CloudSat observations using radiosonde measurements and which has the great potential for studying the multi-layered cloud structures over the globe and important in climate point of view. The present study provides the complete picture of knowledge about the occurrence of multi-layered clouds at Trivandrum using both ground and space based measurements. The output of present study will aid to the modellers for better representation of cloud vertical structures in global circulation models.

\section{Acknowledgments}

Authors are thankful to Wyoming University for providing the radiosonde data and CloudSat team for providing the 2B-Geoporof-Lidar data. The authors are very grateful to Mr. Manoj Kumar Mishra, SPL for providing the MPL data and Dr. N.V.P. Kiran Kumar, SPL for helping in code for extracting the multi-layered cloud information using radiosonde.

\section{Conflict of interests}

The authors declare that there is no conflict of interests regarding the publication of this paper.

\section{References}

Jin, H., \& Barner (2007). Detecting cloud vertical structure from radioosnde and MODIS over Arctic first-year sea ice. Atmos. Res., 83, 64-67.

Marchand, R., Mace, G. G., Ackerman, T., \& Stephens, G. (2008). Hydrometeor detection using Cloudsat: An Earth-orbiting 94-GHz cloud radar. J. Atmos. Oceanic Technol., 25, 519-533, 2008.

Randall, D. A., Harshvardhan, D. A. D., \& Corsetti, T. G. (1989). Interactions among radiation, convection, and large-scale dynamics in a general circulation model. J. Atmos. Sci., 46, 1943-1970.

Reddy, N., Venkat Ratnam, M., Basha, G., \& Ravikiran, V. (2018). Cloud vertical structure over a tropical station obtained using long-term high-resolution radiosonde measurements. Atmos. Chem. Phys., 18, 11709-11727.

Stephens et al. (2002). The CloudSat mission and the A-train - A new dimension of space-based observations of clouds and precipitation. Bull. Amer. Meteor. Soc., 83, 1771-1790.

Subrahmanyam, K. V., \& Kumar, K. K. (2018). CloudSat observations of Multi-layered clouds across the globe. Climate Dynamics.

Wang, J., \& Rossow, W. B. (1995). Determination of cloud vertical structure from upper air observations. J. Appl. Meteorol., 34, 2243 -2258.

Wang, J., \& Rossow, W. B. (1998). Effects of cloud vertical structure on atmospheric circulation in the GISS GCM. J. Climate, 11, 3010-3029.

Wang, J., Rossow, W. B., \& Zhang, Y. (2000). Cloud Vertical Structure and Its Variations from a 20-Yr Global Rawinsonde Dataset. J. Clim., 13, 3042-3056.

Wang, J., Rossow, W. B., Uttal, T., \& Rozendal, M. (1999). Variability of cloud vertical structure during ASTEX observed from a combination of rawinsonde, radar, ceilometer, and satellite. Mon. Weather Rev., 127, 2482-2502.

Webster, P. J., \& Stephens, G. L. (1984). Cloud-radiation interaction and the climate problem. In J. T. Houghton (Ed.), The Global Climate (pp. 63-78). Cambridge Univ. Press, New York.

Zhang, J., Chen, H., Li, Z., Fan, X., Peng, L., Yu, Y., \& Cribb, M. (2010). Analysis of cloud layer structure in Shouxian, China using RS92 radiosonde aided by $95 \mathrm{GHz}$ cloud radar. J. Geophys. Res., 115.

\section{Copyrights}

Copyright for this article is retained by the author(s), with first publication rights granted to the journal.

This is an open-access article distributed under the terms and conditions of the Creative Commons Attribution license (http://creativecommons.org/licenses/by/4.0/). 